\title{
Understanding the benefits of migration: Multigenerational transmission, gender and educational outcomes of Turks in Europe
}

Sait Bayrakdar ${ }^{\mathrm{a}}$ and Ayse Guveli ${ }^{\mathrm{b}}$

${ }^{a}$ School of Education, Communication and Society, King's College London, London, UK; ${ }^{b}$ Department of Sociology, University of Essex, Colchester, UK

Corresponding author: Sait Bayrakdar (sait.bayrakdar@kcl.ac.uk)

School of Education, Communication \& Society, King's College London

Waterloo Bridge Wing, Franklin-Wilkins Building

Waterloo Road, London, SE1 9NH, UK

Biographies

Sait Bayrakdar is a Research Associate in the School of Education, Communication, and Society at King's College London and one of the co-investigators of the ESRC-funded “Opportunity, equality and agency in England's new VET landscape: A longitudinal study of post-16 transitions" project. Sait's research focuses on social stratification, education, migration and various forms of inequality over the life course.

Ayse Guveli is Reader in the Department of Sociology at the University of Essex. Her research focuses on social stratification and mobility, international migration, religion, families and quantitative research methods. She led the 2000 Families project which aimed to reveal the persisting impact of migration on migrants and their multigeneration descendants in origin and destination countries.

Funding

This work was supported by NORFACE (New Opportunities for Research Funding Agency Co-operation in Europe) under the grant number [235548].

Disclosure Statement

No potential conflict of interest was reported by the authors.

\section{ORCID}

Sait Bayrakdar http://orcid.org/ 0000-0003-0244-138X

Ayse Guveli https://orcid.org/0000-0003-3679-0238 


\begin{abstract}
Research commonly compares the educational outcomes of migrants and the second generation to their native peers in destination countries, often finding the former groups lagging behind in education. Their outcomes are rarely compared to their non-migrant peers in the origin countries. Using the dissimilation from origins perspective, we ask whether Turkish-origin men and women in Europe benefit from migration by comparing their educational outcomes to non-migrants in Turkey. At the same time, we comparatively examine the intergenerational transmission of education to determine to what extent individuals capitalise on their parents and grandparents' resources. Analysing the novel 2000 Families data, we show that migrants and their descendants in Europe obtain higher education than their non-migrant peers in Turkey. While both men and women experience educational benefits from migration, women's gains are higher. Another salient finding is that Turkishorigin parents in Europe are less able to pass on their socioeconomic resources to their children than their counterparts in Turkey. Overall, the findings corroborate the theory of the dissimilation of Turkish-origin Europeans from their Turkish peers in educational attainment.
\end{abstract}

Keywords: educational outcomes; international migration; gender; intergenerational transmission; dissimilation

Word count: 8832 words excluding tables, figures and online appendices. 


\section{Introduction}

A plethora of studies compare the education of first and second-generation migrants with native populations across a range of countries in Europe, but we have a weaker understanding of where migrants and their descendants stand with respect to their comparators in the origin countries. This type of comparison is more common in the US (Thomas and Znaniecki 1918; Massey et al. 1987). It is emerging in Europe (Beauchemin et al. 2015; Guveli et al. 2016; Guveli et al. 2017), but it is yet to be fully realized.

Both origin and destination countries are not static but dynamic; non-migrants in both societies face contextual transformations. Therefore, change and stability in migrants' and their descendants' lives should be analysed relative to these transformations in both societies. That is, research should also include a comparison group of non-migrants in the origin countries. Only this assessment can reveal the consequences of migration for people with migration background and will generate a broader and transnational understanding of the dynamics of international migration. To further this line of analysis, in this article we examine the educational outcomes of men and women of Turkish background in Europe and the intergenerational transmission of education, comparing their situation to that of nonmigrants in Turkey. ${ }^{1}$

Turks are a logical choice for this type of analysis, as they represent the largest nonEU migrant group in Europe. The group has a long migration history and specific origin country characteristics - they are predominantly Muslim, for example. Migration started over a half century ago under the 'guest worker' program, and many of these early migrants settled in their destination countries (Akgunduz 2008). The children and grandchildren of the 'guest workers' now constitute a significant share of the population in Western European countries. Their relatively low socio-economic achievement is a repeated and worrying finding of country-specific and comparative studies (Crul and Doomernik 2003; Heath, Rothon and 
Kilpi 2008; Van Tubergen and Van de Werfhorst 2007). However, these studies typically compare Turkish origin people with the natives of their European destination countries, which might not be the best comparison to reveal the consequences of migration. To reveal the impact and gains or losses of migration, research should compare migrants and their offspring to their counterparts in the origin societies. The 2000 Families dataset (Guveli et al. 2016) gives us an opportunity to do so.

Despite the risks and challenges, people move to improve their own and their children's life prospects, but the extent to which they succeed has been questioned. When they are compared to natives in the destination societies, for example, research generally finds a lag in migrant women's and men's employment likelihood (Donato, Piya and Jacobs 2014). Yet a few small-scale studies comparing migrants to those in origin countries find migration has benefits, especially for women (Hondagneu-Sotelo 1994; Pessar 2005). Largescale research on the impact of migration on women is rare, with some exceptions (Dollmann 2017; Fleischmann et al. 2014; Zuccotti et al. 2017), but to reveal the impact of migration and shed further light on the findings of the small-scale studies, research should include a comparison group in the origin countries.

There is a vast body of research on multi-generational social reproduction in majority populations (Bol and Kalmijn 2016; Breen 2018; Chan and Boliver 2013; Erola and Moisio 2007; Hertel and Groh-Samberg 2014; Mare 2011; Modin, Erikson and Vågerö 2012; Møllegaard and Jæger 2015; Pfeffer 2014). This focus is rarely found in international migration studies. In one exception, when Telles and Ortiz (2008) include three to fourgeneration descendants of Mexican migrants in the US, they find the effects of migration last for generations. Except Guveli et al. (2017), until now, no other work has integrated an origin country comparison and multiple family generations. Using the 2000 Families data allows us to do so. 
In what follows, we look specifically at education. Educational expansion in the European countries has increased the opportunities for all segments of society, including the offspring of migrants. Turkey has also seen an expansion in education, and this improvement may have reduced the benefits of migration in terms of educational outcomes for the descendants of migrants. To see if migration has an enduring effect on education, we investigate educational transmission over three generations by comparing the educational outcomes of male and female Turks in Europe and Turks in Turkey.

We pose three research questions, setting them within the dissimilation from origins theoretical framework. The first two focus on the dissimilation of migrants from those left behind in the origin country for men and women separately. The first of these compares the education attainment of Turks in Europe and Turkey. Then, drawing on the literature on the consequences of migration on men and women (Donato, Piya and Jacobs 2014), the second considers the effect of gender. The third question probes the impact of migration across three generations to look for a possible dissimilation from social origins/ancestor. That is, the three questions combine two types of dissimilation mechanisms: dissimilation from origin country and dissimilation from social/family origin. The questions read:

1) To what extent does the educational attainment of Turks in Europe differ from that of nonmigrants in Turkey?

2) To what extent is there a gender gap in educational outcomes for Turks in Europe and Turks in Turkey? If there is a gap, how does it differ between these groups?

3) To what extent does intergenerational transmission of education to children and grandchildren show different patterns in migrant families and non-migrant families?

We aim to show the enduring impact of migration on the educational outcomes of men and women using the unique 2000 Families data (Guveli et al. 2016) collected in five high sending regions in Turkey by sampling migrant and non-migrant ancestors and their 
three-generation descendants. While it is almost impossible to realize counterfactual research in migration, the 2000 Families design includes most features of a counterfactual approach and is therefore unique in large-scale migration studies. It offers the opportunity to study migrants and their three-generation descendants in European countries, and their comparators from the same regions of origin in Turkey.

This research contributes to the literature on international migration, social mobility, and gender studies in three ways. First, it reveals the impact of migration on education by comparing migrants and their descendants with non-migrants and their descendants, using complete family genealogies. Second, it tests the hypothesis that women gain more from migration in the long run than men (Pessar 1984). Third, it explores intergenerational transmissions over three generations in a migration context. The three-generation transmission model provides a better understanding of how family resources may shape educational outcomes in a migration context where transmission may be disrupted (Nauck, Diefenbach and Petri 1988).

\section{Significance of Turkish Migration to Europe and Education in Turkey}

Four characteristics make the Turkish origin migrants and their descendants in Europe relevant for a study of change and stability across multi-generations and across origin and destination contexts. First, they form the largest non-EU origin group with an estimated five million members. Size matters: larger migrant groups are better at establishing their ethnoreligious organisations, but they are slower in integration processes (Esser 2004).

Second, Turks in Western Europe are predominantly labour migrants. They started to arrive under the guest worker program in the early 1960s. After the program ended in 1974, about 70 per cent of these pioneering migrants returned to Turkey (Guveli et al. 2016). Overall, however, migration continued to expand, with some seeking family unification and formation 
and others seeking asylum or education. The grandchildren of the labour migrants now represent a significant group in the European destination countries, and migration flows are continuing, albeit with shifts in migrant types.

Third, Turks are distributed in about ten Western European countries; about 60 per cent of them in Germany, 14 per cent in France and 12 per cent in the Netherlands. They also appear in significant numbers in other countries such as Belgium, Austria, Denmark, Sweden, Switzerland, Norway, and the UK. Fourth, Turks are overwhelmingly Muslim. They introduced Islam to the wider public in Europe in the 1960s along with other Muslim labour migrants. Religion is known to be an important factor in the settlement and integration of migrant groups (Herberg 1955; Smith 1978; Ersanilli and Koopmans 2011).

The benefits and losses of migration should be understood in the context of the social and economic developments taking place in both destination and origin societies. Education is our present focus. Turkey has undergone substantial changes since the first guest worker program started in 1961 (Pamuk 2012), but it still lags behind Western European receiving countries. Figure 1 shows the share of the population with tertiary education for men and women between the 1980s and 2017 for Turkey, Germany, France, and the Netherlands (three largest receiving countries). Clearly, access to tertiary education in Turkey has improved considerably. Tertiary enrolment has traditionally been very low, but it gradually rose and made a sharp jump in the 2000s, narrowing the gap in the last decade. ${ }^{2}$

\section{--- Insert Figure 1 ---}

When we look at the genders separately, we see women in Turkey made substantial progress in gross tertiary school enrolment between 1991 and 2017, rising above 30 per cent, even catching up with Germany in 2017 (Figure 1). Overall, women in Turkey have 
increasingly higher levels of education, closing the gender gap in education and becoming increasingly similar to women in Western European countries where the educational gender gap is exceptionally low and where, in some countries, women are ahead of men. Despite its narrowing, a considerable gap between Turkey and Western European countries remains, making educational attainment a useful way to approach migrant success.

\section{Theoretical Perspectives and Hypotheses}

\section{Dissimilation from origins}

Most studies use assimilation theories to explain migrant trajectories by comparing migrants and their offspring to natives or to other migrant groups in the destination countries (Alba and Nee 2009; Portes 1997). Briefly stated, they examine the extent to which migrants and their descendants become similar to natives. Recent studies have discussed the limitations of these destination country perspectives and proposed extending research beyond the boundaries of nation-states to better understand the processes of international migration (Amelina et al. 2012; FitzGerald 2012; Guveli et al. 2017). As these processes are international, research should include a comparison of migrants to those left behind. In a very early example of this, Thomas and Znaniecki's (1918) influential work compared migrants in America with those left behind in Europe. This research tradition continued in the US with Massey and colleagues (Massey et al. 1987) but is only emerging in Europe (Beauchemin et al. 2015; Guveli et al. 2016).

The dissimilation from origins theoretical framework basically refers to the process of becoming different. FitzGerald (2012) suggests the notion of homeland dissimilation to reveal changes in migrants' lives and to show how different they become from non-migrants in the 'homeland'. Guveli et al. (2017) developed the dissimilation from origins framework to trace two processes. The first process, dissimilation from origin country, indicates changes 
and continuities in migrants' lives compared to non-migrants' lives in the origin country; the second process, dissimilation from social origin, traces changes between grandparents, parents and grandchildren. In what follows, we use this framework to shed light on change and continuity in the educational progress of migrants vs non-migrants, ancestors vs descendants and men vs women to better understand the enduring impact of migration.

\section{Movers and Stayers Hypothesis}

Recent studies show that although Turks in Europe have lower educational outcomes than natives in their European destination countries, they are more successful than Turks in Turkey (Zuccotti et al. 2017). Dustmann, Frattini and Lanzara (2012) find that Turks in Europe perform better in mathematics than Turks in Turkey but not as well as natives in Germany. They argue that better school and 'peer' quality improve the scores of Turks in Europe over their stay-at-home comparators. Zuccotti and her colleagues (2017) also show that Turkish migrants and the second generation in Europe attain higher levels of education than Turks in Turkey, albeit not as high as native populations in Europe. However, their study compares Turks in Europe to a representative sample of Turks in Turkey. This is not an ideal comparison, because the majority of Turks in Europe originate from rural or semi-rural regions. Guveli and her colleagues (2016) use the 2000 Families dataset to improve the comparison groups of non-migrants in Turkey but they do not focus on gender and migration generations. To expand upon this approach, we use the 2000 Families data and focus on gender and multi-generational transmission among migration generations.

Shaped by the events in previous century (such as development of national education systems, adoption of compulsory education and increasing levels of literacy) across Europe and reinforced by the democratic expansion following the World War I (Muller et al 1997), educational expansion in Western European countries has opened pathways to education for 
the wider public and facilitated access for children from all social classes. Since the World War II, a new wave of educational expansion coupled with economic growth and restructuring has opened the doors to higher levels of education and wider public obtained access to upper secondary and tertiary education (Hadjar and Becker, 2009). While recent research documents that expansion does not necessarily increase social mobility (Bukodi and Goldthorpe 2016; Rotman, Shavit and Shalev 2016), social mobility has remained fairly stable in the Western European countries since 1970s (Breen 2004). ${ }^{3}$ Although Turkey has also expanded its education system, this happened after the mid-1990s. Social mobility is comparatively higher in European destination countries than in Turkey where educational achievement is relatively more dependent on social background (Zuccotti et al. 2017).We might expect, then, that the descendants of Turkish migrants in Europe will have a higher level of education than the descendants of non-migrants who stayed in Turkey (Hypothesis 1). That is, we expect Turkish-origin people in Europe to become dissimilar to their counterparts in Turkey in terms of education achieved.

\section{Hypothesis on Gender Gap in Education of Turks in Europe and Turkey}

The classic research on international migration to Western countries expects an improvement in women's household and societal conditions (Hondagneu-Sotelo 1992). Women escape the patriarchal structures of their origin societies and find opportunities to empower their household and socioeconomic positions using the opportunities available in the destination countries (Hondagneu-Sotelo 1992). Not all scholars agrees with this thesis; some argue that migrant women may seek to maintain traditional role patterns in order to preserve the stability and cohesion of their family and community in unfamiliar and hostile new societies (Abadan-Unat 1977; Pessar 2003). Studies in this vein are pessimistic about the wider emancipating power of migration on women. This mostly represents small-scale research, 
and studies often do not include a comparison to those in the origin countries (Abadan-Unat 1977; Hondagneu-Sotelo 1992). Some studies, mostly large-scale research, even find a negative impact of migration on women, with a 'double disadvantage' compared to both migrant men and native women in the destination countries (Boyd 1984; Donato, Piya and Jacobs 2014).

Whilst findings on women's outcomes are mixed, in Europe, there is some evidence that migration is empowering Turkish women (Eroğlu 2018; Huschek et al. 2011).

Lesthaeghe and Surkyn (1995) show a slow but clear shift towards more female autonomy for Moroccan and Turkish women in Belgium. And according to more recent research on attitudes to gender equality, migrants and their descendants adopt stronger egalitarian views than their non-migrant counterparts (Guveli et al. 2016). Idema and Phalet (2007) show a shift among female second-generation Turks towards more egalitarian gender-role values. By the same token in an analysis of the 2000 Families data, Eroğlu $(2018$, p. 1) finds that 'international migration increases the tendency for spouses to jointly decide on their finances by weakening the intergenerational transmission of traditional financial decision-making behaviors and gender ideologies'. Increasingly egalitarian attitudes are confirmed by Guveli et al (2016) in their research on migrant and non-migrant Turks. Using the European Social Survey, Zuccotti et al. (2017) also show female Turks in Europe are doing particularly well compared to non-migrant Turkish women in terms of education.

Education is one of the most important means for women in traditional communities to break away from restrictive individual and social conditions (Hondagneu-Sotelo 1992), and Western Europe offers more educational opportunities. Hence, we expect Turkish women in Europe will benefit more from their families' migration than their male peers in Europe (Hypothesis 2). That is, women will become more dissimilar to their male peers in Europe and their female counterparts in Turkey. 


\section{Hypotheses on Transmission across Generations among Turks in Europe and Turkey}

We are also interested in whether parents' (dis)advantages are passed on to their children, especially whether there are differences between migrants and non-migrants. International migration is said to disrupt reproduction across generations (Nauck, Diefenbach and Petri 1988). Arguably, this may include a disrupted transmission of the disadvantages of a lack of education and/or belonging to a lower social class. While the resources of parents may still have an effect on the socio-economic outcomes of children from migrant families (Phalet, Deboosere and Bastiaenssen 2007; Fakjaer 2007), this effect is found to be smaller for children from migrant families compared to their native peers (Levels and Dronkers 2008; Phalet and Heath 2010).

In theory, then, migrants with low education have the opportunity to disrupt the trajectory and further their children's life chances in the egalitarian European societies in which their life chances are better than those in their origin countries (Ponce 2018). In other words, their children's education becomes independent from their own. By contrast, educational reproduction is higher in Turkey (Zuccotti et al. 2017); that is, parents who stay put are more likely to raise children with similar levels of education as their own education. Therefore, we expect Turkish parents in Europe are less 'successful' in passing on their education to their children than parents in Turkey (Hypothesis 3).

Transmission across multiple generations, that is, grandparental influence, is rapidly gaining interest in stratification research (Bol and Kalmijn 2016; Chan and Boliver 2013; Erola and Moisio 2007; Hertel and Groh-Samberg 2014; Mare 2011; Modin, Erikson and Vågerö 2012; Møllegaard and Jæger 2015; Pfeffer 2014). In the international migration literature, studies of the persisting social inequalities and social origins of migrants across 
multiple generations are rare. Extending the research beyond the second generation is key to understanding the impact of migration in the longer term.

Migration is likely to function as an interruption in the transmission process between grandparent and grandchild, with mechanisms similar to those of the parental transmission. Some research shows the grandparent effect is mediated by parental resources and skills; that is, after controlling for parental socioeconomic influences, there is no relationship between grandparents' and grandchildren's socioeconomic conditions (Jaeger 2012). Others argue that grandparents play a role in some conditions (Mare 2011). For example, they influence their grandchildren's socioeconomic outcomes when parents are unable to provide guidance and resources or when social stratification processes are shaped more by social origins than by redistributive state policies (Deindl and Tieben 2017). Turkish society has weaker meritocratic structures, suggesting the possibility of a stronger parental and grandparental impact on educational outcomes. In contrast, Turkish-origin Europeans are more likely to become independent of their ancestors by taking advantage of the opportunities of their affluent and relatively open destination societies. We therefore expect grandparental socioeconomic characteristics are less significant for European Turks than Turks in Turkey (Hypothesis 4).

Recent research shows parental co-residency affects the transmission of parental resources (de Leeuw, Kalmijn and van Gaalen 2018), suggesting physical proximity may shape the support parents and grandparent provide. In the context of international migration, family members may live in different countries, and this may weaken the transmission. We therefore take into account the country of residence of parents and grandparents.

To sum up, the weaker transmission of (low) education among European Turkish families will accelerate the dissimilation from social origins (parents and grandparents) and 
generate more individual change for Turkish-origin people in Europe than for Turks in Turkey.

\section{Data and Methods}

\section{Research Design}

The 2000 Families dataset (Guveli et al. 2016) includes information about migrant and nonmigrant families from five high-sending regions (i.e. Acıpayam, Akçaabat, Emirdağ, Kulu and Şarkışla) in Turkey. The migration history of the male ancestor (G1) defined the selection of the families, and the migrant ancestors were selected on the basis of four criteria: the ancestor 1) might be alive or dead, 2) is or would have been between 65 and 90 years old, 3) grew up in the region, and 4) moved to Europe between 1960 and 1974 and stayed in Europe for at least five years. The ancestor of the non-migrant family ('the counterfactual') was identified with the same criteria, with one exception: he had not moved to Europe.

To locate the migrant and non-migrant ancestors and their family members, a probability sample of 100 primary sampling units was drawn from the address register of the Turkish Statistical Institute for each region. The addresses were chosen by random walk starting from each primary sampling unit. A quota of 80 per cent migrant ancestors and 20 per cent non-migrant ancestors applied in obtaining about 400 families for each region.

Using the contact details of family members, a proxy interview per family was administrated on one well-informed family member (proxy informant) to collect factual information on the migration history and socioeconomic situation of all adult descendants of the migrant and non-migrant ancestors. Face-to-face interviews were carried out with the proxy-informants present in the regions and phone interviews with those who were not present between 2010 and 2012. The final dataset based on the proxy interviews has information about 19,477 individuals spanning three family generations nested within 1,544 
families (for more detail, see Ganzeboom et al. 2016). Previous analysis of the reliability of the data from proxy interviews shows no bias introduced by proxy informants' characteristics (Bayrakdar, 2015).

Our units of analysis are the children (G2) and the grandchildren (G3) in the families. We have not included the ancestors (G1 -Grandparents) in the regression models as they had completed their education in Turkey before migration. We also distinguish migration generations in ten destination countries (Germany, the Netherlands, France, Austria, Belgium, Denmark, Sweden, Switzerland, the UK, and Norway).

We run our analysis in two parts: the first part (pooled models) shows the outcomes of children (G2) and grandchildren (G3). The second part (grandparent models) analyses the outcomes of only the grandchildren (G3). After eliminating the cases with missing data, the total sample size is 12,083 for the pooled models and 5,923 for the grandparent models.

The 2000 Families dataset facilitates our investigation of the impact of grandparents for two reasons. Firstly, it includes families from similar backgrounds, such as region of origin, thus minimizing the effect of possible unobservable factors on migrants. Secondly, it collects information on the lineages of the grandparents from the same birth cohort, thus eliminating the variance generated by the conditions affecting the joint survival of grandparents and their grandchildren (Breen 2018). The 2000 Families dataset also includes extensive information about the grandparents $(\mathrm{G} 1)$, their parents $(\mathrm{G} 0)$, parents $(\mathrm{G} 2)$, and grandchildren (G3), allowing us to control for the selection of migrants and to explore interactions in place of residence for parents and grandparents.

\section{Variables}

The dependent variable is the 'highest educational level obtained'. It is an ordinal variable comprising six categories: 'primary dropout', 'primary', 'lower secondary', 'higher 
secondary', 'tertiary, and 'post-tertiary'. The proxy informant reported the highest completed education level for each adult family member, using the same educational categories for all countries. These categories represent the educational levels in Turkey, but they are compatible with the European Social Survey's common educational measure. There is an extensive literature on the difficulties of comparing educational categories/levels across countries (Schneider 2008; Schroder and Ganzeboom 2013). Using the origin country's educational levels/categories to compare the level of education of migrants and their descendants to those in the origin country has been suggested as a solution to the problem of comparability (Ichou 2014).

The independent variables in the pooled models include gender, migration status, parents' education and occupational status, and family generation. The analysis in the grandparent models includes all variables in the first part except the family generation, as this model only includes the G3 family members (grandchildren). In addition, the grandparent models include education and occupational status of the grandparent, as well as the information on where parents and grandparents live. The descriptive statistics of the variables for the pooled models and the grandparent models are presented in the appendix.

In the models, women are coded as 1 and men as 0 . As we are interested in the impact of different migrant generations on educational outcomes, we construct five migration statuses using the country of birth and the age of migration to Europe. These statuses are: (1) non-migrants including the individuals who stayed Turkey, (2) first-generation including those who migrated to Europe after the age of six and before completing their education, (3) 1.5 generation comprising individuals who migrated to Europe before the age of seven, (4) second generation including those who were born in Europe, and (5) returnees comprising those who were born or lived in Europe but migrated to Turkey. 
Family generations comprise two groups: the children (G2) and the grandchildren (G3) of the ancestor (G1). We measure the socioeconomic characteristics of the parents by their education level and occupational status. Parental education is measured in the same way as our dependent variable, and it comprises six categories. For parental and grandparental occupation, we use the ISEI, International Socioeconomic Index of Occupations, as it allows international comparison of occupational status (Ganzeboom and Treiman 1996). Finally, we control for age, the region of origin, sibship size and whether parents and grandparents live in Europe.

\section{Methodology}

We use OLS regression which allows to simultaneously explore the effects of multiple independent variables and makes the interpretation of the results easier. ${ }^{4}$ Both the pooled models and the grandparent models are nested models and enable a comparison of the coefficients and the effects across the models. We also cluster the cases at the family level, as the individuals are nested within the families. Finally, as a part of our sensitivity checks, we use the occupational status of the father of the first-generation ancestor (G1) to control for migrant selectivity, and we include destination country dummies to control for country differences. These models are presented in the online appendix.

\section{Impact of Migration and Migrant Selectivity}

As mentioned at the outset, research commonly compares the educational attainment of migrants and their descendants to the natives in destination countries. To reveal the impact or the benefits of migration, however, researchers should compare migrants' and their descendants' educational attainment to their counterfactuals in the origin countries. Yet a counterfactual research design is hard, if not impossible, to realize in migration studies 
because researchers are unable to allocate migration status to random individuals (see also Pearl and Machenzie 2018). The decision to migrate might be associated with resources and aspirations, and migrants are thought to be different from their non-migrant counterparts in terms of their pre-migration socioeconomic resources and risk-taking behaviours (Borjas 1987; Ichou and Wallace, 2019). Some argue that the differences between movers and stayers could partly or fully be explained by migrant selectivity (van de Werfhorst and Heath 2019). Although researchers have sought ways to reveal migrant selectivity in different contexts (Van Tubergen et al. 2004; Dronkers and De Haus 2012), selectivity has rarely been directly tested.

The 2000 Families dataset provides retrospective pre-migration information on the socioeconomic status of family members. These unique data are the most appropriate existing measures to control for socioeconomic differences between migrants and non-migrants before the migration took place; they are also proxy variables for potential differences in risk-taking behaviour and aspirations. By using these data, we are able to minimise migrant selectivity and hence isolate the impact of migration on educational attainment.

--- Insert Table 1 ---

Table 1 shows the occupational status (ISEI) of the father (G0) of the migrant and non-migrant ancestors (G1) and the mean education and occupational status of the migrant and non-migrant ancestors (G1). The occupational status of the migrant ancestor's father (G0) is not significantly different from the occupational status of the non-migrant ancestor's father. That is, in terms of their fathers' socioeconomic conditions, the pioneer migrants were not a selective group of people. However, their own socioeconomic characteristics show a different picture. On the one hand, the level of education of the migrant ancestors (G1) is 
higher than that of their counterparts who did not move to Europe, showing a positive selection of migrants. On the other hand, their occupational status shows negative selection because their pre-migration occupational status is lower than that of the non-migrant ancestors left behind. It should be noted, however, that these differences between the migrant and non-migrant ancestors are not large. Although it is farfetched to think these marginal differences account for the variances in educational outcomes in the subsequent family generations, we add these family socioeconomic backgrounds in our regression analyses to control the findings for positive and negative selection of migration.

\section{Results}

\section{Migration Benefits and Gender Gap in Education}

Figure 2 shows the educational outcomes for amalgamated categories by family generations and migration status. For migrants and non-migrants alike, education is higher among the grandchildren (G3), although the differences between the children (G2) and grandchildren (G3) are small for the second generation in Europe. G2 and G3 taken together, the highest educated groups are the 1.5 and second-generation Turks in Europe, although the firstgeneration grandchildren (G3) have the highest rate of tertiary education. They are followed by the first-generation migrants and returnees. In other words, Figure 2 shows that migrant generations who live or have lived in Europe obtain, on average, higher levels of education than non-migrant generations in Turkey. These descriptive findings suggest Turks in Europe benefit from the migration decision of their parents and grandparents.

\section{--- Insert Figure 2 ---}

Figure 3 shows educational outcomes by gender and migration status. The findings present women in Europe are more likely to have tertiary education than men. This 
difference is largest for those born in Europe (second generation). Women in Turkey do not fare so well: non-migrant men in Turkey have substantially higher levels of education than women. These differences suggest migration generates educational benefits, but the gains are stronger for women. To probe this possibility, we investigate the gender differences in more detail in multiple regression models.

--- Insert Figure 3 ---

Table 2 shows the linear regression results for educational outcomes of the children and grandchildren (G2 and G3). Model 1 is the base model, including age, gender, sibship size, region of origin and family-generations as controls, along with migration status. Models 2 and 3 add parental characteristics and interaction terms between gender and migration status, respectively.

--- Insert Table 2 ---

Model 1 confirms our descriptive results suggesting that grandchildren (G3) obtain significantly higher levels of education than children (G2). In addition, women in general have significantly lower levels of education than men. Finally, controlling for other factors, the first, 1.5, and second-generation individuals with a Turkish background in Europe obtain significantly higher levels of education than their non-migrant comparators in Turkey. This supports Hypothesis 1.

Model 2 shows the effects of parental characteristics. Both parental education and occupational status have positive and significant effects on education, a finding in line with the bulk of research on migration and social stratification (Zuccotti et al. 2017). But the coefficients for migration status (first, 1.5, and second generation) change very little between 
Model 1 and Model 2. That is, parental characteristics only slightly account for the differences between the non-migrant generations in Turkey and the migrant generations in Europe.

Model 3 includes the interaction terms between gender and migration status to observe the effects of migration status for men and women (Hypothesis 2). These coefficients show a positive additional effect for the first and second-generation women, but the interaction effect for 1.5 generation women is significant only at the 0.10 level. After including the interaction terms, the coefficients for migration status are reduced indicating that part of the migrant advantage is driven by gender. Whilst migration brings an important advantage for migrants and for their children, then, women have a double advantage. That is, women in Turkey have significantly less education than men in Turkey, but the Turkishorigin women in Europe catch up and even significantly exceed men in their educational attainment. Therefore, they become more dissimilar, supporting Hypothesis 2.

\section{Transmission over Generations}

Our sample in the grandparent models is the grandchildren (G3) in Europe and in Turkey and they include the occupational status and education of parents and grandparents. These models answer our third research question and test Hypotheses 3 and 4.

\section{--- Insert Table 3 ---}

Model 1 in Table 3 is the base model with migration status and grandparental characteristics, along with the control variables. The model reveals the direct and indirect effect of grandparental education and occupation. As expected, first, 1.5 and second-generation individuals have significantly higher education than their comparator non-migrant 
generations in Turkey. This model also shows that the education and occupational status of grandparents have a positive and significant effect on educational attainment.

Model 2 adds parental education and occupation and reveals the extent to which the grandparental characteristics are mediated by parental education and occupation. Whilst only parental education has a significant and positive effect, the grandparental effect remains significant even after controlling for parental characteristics. Put otherwise, grandparents have a direct and also an indirect impact on their grandchildren's educational outcomes. Model 3 demonstrates the coefficients of interaction terms specifying transmissions of parents and grandparents living in Europe. This model shows that having a parent in Europe leads to significantly higher education, but parental transmission of education is weaker for these parents. In other words, parents living in Europe are significantly less able to pass on their education than parents living in Turkey. This is in line with Hypothesis 3, stating that Turks in Europe become independent of their social origins; that is, they become dissimilar to their parents.

Model 3 also shows a weaker effect of grandparent's education and occupation if they are living in Europe, though this effect is not significant. The regression coefficients are small and subtracting the interaction coefficient of education of grandparents living in Europe (0.062) from the main effect (0.082) gives a negligible coefficient of 0.020 . The same applies to the impact of the occupational status of the grandparents living in Europe. Although the coefficients are in line with our expectation that the transmission of grandparents living in Europe is weaker than the transmission of grandparents living in Turkey, Hypothesis 4 is not strongly supported.

\section{Sensitivity Checks}


As part of our sensitivity checks, we rerun our final regression models from Table 2 (pooled models) and Table 3 (grandparent models). Firstly, we include the occupation status of the father (G0) of the ancestor (G1) to control for the pre-migration differences between migrants and non-migrants. Including this information does not change our conclusions and suggests that the differences found between migrant and non-migrant individuals do not stem from migrant selectivity.

Secondly, we include the country of education variable instead of migration status to see to what extent individuals in Europe differ in terms of their education across the destination countries. While the destination country coefficients naturally indicate some degree of variance across countries, all the coefficients are positive, showing that migrants benefit from migration in all destination countries. Among the destination countries in the two sets of models, only the coefficients for Austria and Switzerland in the pooled models are not significantly positive. Therefore, we conclude that our findings are robust across the destination countries in our sample.

\section{Conclusion and Discussion}

Research on international migrants' outcomes overwhelmingly focuses on comparisons between migrants and natives in the destination countries, and findings consistently show non-EU migrants and their descendants lag behind their native comparators in their life prospects. This common approach has contributed a great deal of understanding in the processes of integration into the destination societies. We argue for the need to look furtherspecifically at migrants' peers in the origin countries. Only then will the impact of migration be revealed, and will our understanding of migration dynamics and processes be extended beyond the borders of the nation states of the destination societies (Amelina et al. 2012; Guveli et al. 2017). 
We have examined the effects of migration on the educational outcomes of Turkish women and men across three generations by comparing the children and grandchildren of Turkish labour migrants in Europe to their non-migrant counterparts in the geographic regions of origin in Turkey. We started by asking whether migration benefits migrants and their descendants in terms of education. The short answer is yes, it does. More specifically, Turks in Europe obtain better educational outcomes than those in Turkey (Hypothesis 1). In addition, women benefit more from migration than men in terms of educational attainment (Hypothesis 2). Women in Turkey have lower educational attainment than men, but Turkishorigin women in Europe have caught up to and passed men in both Turkey and Europe to become the most educated group in our sample.

Results on the multi-generation transmission of educational outcomes confirm it is significantly less likely for parents in Europe to pass on their levels of education to their children than parents in Turkey (Hypothesis 3). In other words, individuals in Europe become dissimilar to their comparators in the origin country. We also find that grandparents' resources are important for educational outcomes; even after controlling for parents' resources, there is transmission over three generations (Hypothesis 4). Arguably, grandparents are more involved in their grandchildren's care in countries with weaker social welfare structures (Deindl and Tieben 2017), leading us to explore whether the grandparental effect is stronger in Turkey. Our data demonstrate that grandparents have a significant and positive impact on their grandchildren's education, which also forms a novel contribution to the literature on multigenerational transmission (Breen 2018). However, we cannot confirm that grandparental transmission is weaker for Turks in Europe where there are relatively more social welfare facilities.

The study makes a substantial contribution to gender, international migration, and social stratification studies by comparing individuals with a migration background to their 
peers in the origin country across three generations. The findings are striking: overall, Turks in Europe enjoy educational advantages, and women benefit more, a double advantage, than men, providing robust confirmation of the classic hypothesis that migration empowers women (Hondagneu-Sotelo 1992).

The dissimilation from origins perspective is a useful framework for a comparative study of the changes and continuities in migrants' and their descendants' lives. Our research substantiates the claim that migration disrupts continuity and transmission in the family (Nauck, Diefenbach and Petri 1988), arguably an advantage for families with lower socioeconomic resources. Our dissimilation from origins approach uniquely enables to trace changes and stabilities after migration which typical assimilation studies are unable to reveal. Comparing migrants and their descendants to non-migrants in the origin societies is important not only to show the impact of migration but also to challenge the depictions of migrants being static and missing any form of agency or resilience. Our findings show that Turkish women make effective use of the relatively more gender-equalitarian opportunities and pursue higher educational outcomes in the European societies, more so than their male counterparts in the same context.

Our research presents convincing evidence that migration benefits women more than men in terms of educational attainment, suggesting an exciting new direction for future research in order to make novel contribution to the long-lasting discussion about the emancipating power of migration on women. Other research is skeptical about the positive relationship between migration and women's independence (Abadan-Unat 1977; HondagneuSotelo 1994). Some show that migration empowers women in some dimensions while it reinforces traditional gender roles in other indicators (Parrado and Flippen 2005). The 2000 Families dataset includes wealth of information and it could therefore be used to further investigate these claims, which will be our next line of research. 


\section{Endnotes}

${ }^{1}$ We use 'Turks in Europe' to delineate those who moved or whose parent(s) or grandparent(s) moved from Turkey and are living in European destination countries. We are not referring to ethnicity or citizenship.

${ }^{2}$ High school enrolment rates show very similar trends.

${ }^{3}$ The studies comparing social mobility levels across countries show differences in their methods and measurements as well as their conclusions. That said, almost all studies show that Western European countries show high levels of social mobility with Scandinavian countries and the Netherlands being in the lead and France and Germany being rather close to the mid-levels of the rankings. For an extensive review of the conclusions as well as crosscountry differences see Breen and Jonsson's (2005) review of research on educational attainment and social mobility.

${ }^{4}$ Ordinal logistic regression models yield similar results. 


\section{References}

Abadan-Unat, N. 1977. "Implications of Migration on Emancipation and Pseudoemancipation of Turkish Women.” International Migration Review, 11(1): 31-58.

Akgündüz, A. 2008. Labour Migration from Turkey to Western Europe, 1960-1974: A Multidisciplinary Analysis. Farnham: Ashgate.

Alba, R. D., and V. Nee. 2009. Remaking the American Mainstream: Assimilation and Contemporary Immigration. Cambridge: Harvard University Press.

Amelina, A., D. N. Devrimsel, T. Faist, and N. G. Schiller. 2012. Beyond Methodological Nationalism: Research Methodologies for Cross-border Studies. New York: Routledge.

Bayrakdar, S. 2015. "Educational Outcomes and Mobility in Turkish Migrant and Nonmigrant Families" PhD diss., University of Essex.

Beauchemin, C., J. Nappa, B. Schoumaker, P. Baizan, A. Gonzalez-Ferrer, K. Caarls, and V. Mazzucato. 2015. "Reunifying Versus Living Apart Together Across Borders: A

Comparative Analysis of sub-Saharan Migration to Europe." International Migration Review 49 (1): 173-99.

Bol, T., and M. Kalmijn. 2016. "Grandparents' Resources and Grandchildren's Schooling: Does grandparental involvement moderate the grandparent effect?" Social Science Research 55: $155-70$.

Borjas, G. J., 1987. "Self-selection and the Earnings of Immigrants." American Economic Review 77 (4): 531-53

Boyd, M. 1984. "At a Disadvantage - the Occupational Attainments of Foreign Born Women in Canada." International Migration Review 18 (4): 1091-119.

Breen, R. 2004. Social Mobility in Europe. Oxford: Oxford University Press.

Breen, R. 2018. "Some Methodological Problems in the Study of Multigenerational Mobility." European Sociological Review 34 (6): 603-11.

Breen, R., and J. O. Jonsson. 2005. "Inequality of opportunity in comparative perspective: Recent research on educational attainment and social mobility." Annual Review of Sociology 31: 223-243. 
Bukodi, E., and J. H. Goldthorpe. 2016. "Educational Attainment-relative or Absolute-as a Mediator of Intergenerational Class Mobility in Britain." Research in Social Stratification and Mobility 43: 5-15.

Cappellari, L. 2016. "Income Inequality and Social Origins." IZA World of Labor Policy Paper. Bonn: IZA.

Chan, T. W., and V. Boliver. 2013. "The Grandparents Effect in Social Mobility: Evidence from British Birth Cohort Studies." American Sociological Review 78(4): 662-678.

Crul, M., and J. Doomernik. 2003. "The Turkish and Moroccan Second Generation in the Netherlands: Divergent Trends between and Polarization within the Two Groups." International Migration Review 37(4):1039-64.

Crul, M., and H. Vermeulen. 2003. "The Second Generation in Europe." International Migration Review 37(4): 965-86.

de Leeuw, S. G., M. Kalmijn, and R. van Gaalen. 2008. "The Intergenerational Transmission of Educational Attainment among Non-residential Fathers and Their Children." Research in Social Stratification and Mobility 55: 40-50.

Deindl, C. and N. Tieben. 2017. "Resources of Grandparents: Educational Outcomes across Three Generations in Europe and Israel." Journal of Marriage and Family 79(3):769-83.

Dollmann, J. 2017. "Positive choices for all? SES-and Gender-specific Premia of Immigrants at Educational Transitions." Research in Social Stratification and Mobility 49:20-31.

Donato, K. M., B. Piya, and A. Jacobs. 2014. "The Double Disadvantage Reconsidered: Gender, Immigration, Marital Status, and Global Labor Force Participation in the 21st Century." International Migration Review 48: 335-S76.

Dronkers, J., and M. de Heus. 2012. "Immigrants' children scientific performance in a double comparative design: The influence of origin, destination, and community." London: Centre for Research and Analysis of Migration (CReAM), Department of Economics, University College London .

Dustmann, C., T. Frattini, and G. Lanzara. 2012. "Educational Achievement of Secondgeneration Immigrants: An International Comparison." Economic Policy 27 (69): 143-185. 
Eroğlu, Ş. 2018. "Are Movers More Egalitarian than Stayers? An Intergenerational Perspective on Intra-Household Financial Decision-Making." International Migration Review. doi: $10.1177 / 0197918318809923$

Erola, J., and P. Moisio. 2007. "Social Mobility over Three Generations in Finland, 19502000." European Sociological Review 23(2):169-83.

Ersanilli, E., and R. Koopmans. 2011. "Do Immigrant Integration Policies Matter? A Threecountry Comparison among Turkish Immigrants." West European Politics 34 (2): 208-234.

Esser, H. 2004. "Does the "New" Immigration Require a "New" Theory of Intergenerational Integration?" International Migration Review 38(3):1126-59.

Fekjaer, S. N. 2007. "New Differences, Old Explanations: Can Educational Differences between Ethnic Groups in Norway be Explained by Social Background?." Ethnicities 7 (3): 367-389.

FitzGerald, D. 2012. "A Comparativist Manifesto for International Migration Studies." Ethnic and Racial Studies 35 (10): 1725-40.

Fleischmann, F., C. Kristen, including the provision of data with contributions, by analyses instrumental to the research, A. F. Heath, Y. Brinbaum, P. Deboosere, N. Granato, J. O. Jonsson, E. Kilpi-Jakonen, and G. Lorenz. 2014. "Gender Inequalities in the Education of the Second Generation in Western Countries." Sociology of Education 87(3):143-70.

Ganzeboom, H. B. G., and D. J. Treiman. 1996. "Internationally Comparable Measures of Occupational Status for the 1988 International Standard Classification of Occupations." Social science research 25 (3) : 201-239.

Ganzeboom, H. B. G., Sozeri, E. K., Guveli, A., and Bayrakdar, S. 2016. 2000 Families: Migration Histories of Turks in Europe - Data Documentation. VU University of Amsterdam. Guveli, A., B. G. H. Ganzeboom, H. Baykara-Krumme, S. Bayrakdar, S. Eroglu, B. Hamutci, B. Nauck, L. Platt, and E. K. Sözeri. 2016. "2000 Families: Migration Histories of Turks in Europe." GESIS Datenarchiv, Köln. ZA5957 Datenfile Version 1(0). doi: 10.4232/1.12673

Guveli, A., H. B. G. Ganzeboom, H. Baykara-Krumme, L. Platt, Ş. Eroğlu, N. Spierings, S. Bayrakdar, B. Nauck, and E. K. Sozeri. 2017. "2,000 Families: Identifying the Research Potential of an Origins-of-Migration Study." Ethnic and Racial Studies 40(14):2558-76. 
Guveli, A., B. G. H. Ganzeboom, L. Platt, B. Nauck, H. Baykara-Krumme, S. Eroglu, S. Bayrakdar, E. K. Sozeri, and N. Spierings. 2016. Intergenerational Consequences of Migration: Socio-economic,Family and Cultural Patterns of Stability and Change in Turkey and Europe. Basingstoke: Palgrave Macmillan.

Hadjar, A., and R. Becker. 2009. Educational Expansion: Expected and Unexpected Consequences. Vienna: Haupt Verlag.

Heath, A. F., C. Rothon, and E. Kilpi. 2008. "The Second Generation in Western Europe: Education, Unemployment, and Occupational Attainment." Annual Review of Sociology 34(1):211-35.

Herberg, W. 1955. Protestant, Catholic, Jew: An Essay in American Religious Sociology. Garden City, NY: Doubleday \& Co.

Hertel, F. R., and O. Groh-Samberg. 2014. "Class Mobility across Three Generations in the US and Germany." Research in Social Stratification and Mobility 35:35-52.

Hondagneu-Sotelo, P. 1992. "Overcoming Patriarchal Constraints: The Reconstruction of Gender Relations Among Mexican Immigrant Women and Men." Gender \& Society 6: 393415.

Hondagneu-Sotelo, P. 1994. Gendered Transitions: Mexican Experiences of Immigration. California: University of California Press.

Huschek, D., H. A. G. de Valk, and A. C. Liefbroer. 2011. "Gender-role behavior of secondgeneration Turks: The role of partner choice, gender ideology and societal context." Advances in Life Course Research 16(4):164-77.

Ichou, M. 2014. Who They were There: Immigrants' Educational Selectivity and Their Children's Educational Attainment. European Sociological Review 30 (6): 750-765.

Ichou, M., and M. Wallace. 2019 "The Healthy Immigrant Effect: The Role of Educational Selectivity in the Good Health of Migrants." Demographic Research 40 (4): 61-94

Idema, H., and K. Phalet. 2007. "Transmission of Gender-role Values in Turkish-German Migrant Families: The Role of Gender, Intergenerational and Intercultural relations." Zeitschrift Fur Familienforschung 19 (1): 71-105.

Jaeger, M. M. 2012. "The Extended Family and Children's Educational Success." American Sociological Review 77 (6): 903-22. 
Lesthaeghe, R., and J. Surkyn. 1995. "Heterogeneity in Social-Change - Turkish and Moroccan Women in Belgium." European Journal of Population 11 (1): 1-29.

Levels, M., and J. Dronkers. 2008. "Educational Performance of Native and Immigrant Children from Various Countries of Origin." Ethnic and Racial Studies 31 (8): 1404-1425.

Mare, R. D. 2011. "A Multigenerational View of Inequality." Demography 48(1):1-23.

Massey, D. S., R. Alarcon, J. Durand, and H. Gonzalez. 1987. Return to Aztlan: the Social Process of International Migration from Western Mexico. Berkeley: London: University of California Press, 1990.

Modin, B., R. Erikson, and D. Vågerö. 2012. "Intergenerational Continuity in School Performance: Do Grandparents Matter?" European Sociological Review 29(4):858-70.

Møllegaard, S., and M. M. Jæger. 2015. "The Effect of Grandparents' Economic, Cultural, and Social Capital on Grandchildren's Educational Success." Research in Social Stratification and Mobility 42: 11-19.

Müller, W., 1998. "Erwartete und unerwartete Folgen der Bildungsexpansion". Kölner Zeitschrift für Soziologie und Sozialpsychologie, 38: 81-112.

Nauck, B., H. Diefenbach, and K. Petri. 1998. "Intergenerational transmission of cultural capital under the conditions of migration - On the educational achievement of children and adolescents from migrant families in Germany." Zeitschrift Fur Padagogik 44(5):701-22.

OECD. 2018. "Labour force participation rate, by sex and age group."

OECD. 2018. A Broken Social Elevator? How to Promote Social Mobility. Paris: OECD.

Pamuk, Ş. 2012. "Editor's Introduction: Turkey's Experience with Neoliberal Policies and Globalization since 1980." New Perspectives on Turkey 47:5-10.

Parrado, E.A., and C.A. Flippen. 2005. "Migration and Gender among Mexican Women." American Sociological Review 70(4): 606-32.

Pearl, J., and D. Mackenzie. 2018. The Book of Why: the New Science of Cause and Effect. Basic Books. London: Allen Lane.

Pessar, P. 2005. "Women, Gender, and International Migration across and beyond the Americas: Inequalities and Limited Empowerment." Mexico City: UN Population Division. 
Pessar, P. 2003. "Engendering Migration Studies: The Case of New Immigrants in the United States." Pp. 20-42 in Gender and US Immigration: Contemporary Trends, edited by Pierrette Hondagneu-Sotelo. Berkeley: University of California Press.

Pfeffer, F. T. 2014. "Multigenerational approaches to social mobility. A multifaceted research agenda." Research in Social Stratification and Mobility 35:1.

Phalet, K., and A. Heath. 2010. "From Ethnic Boundaries to Ethnic Penalties: Urban Economies and the Turkish Second Generation." American Behavioral Scientist 53 (12): 182450 .

Phalet, K., P. Deboosere, and V. Bastiaenssen. 2007 "Old and New Inequalities in Educational Attainment: Ethnic Minorities in the Belgian Census 1991-2001." Ethnicities 7 (3): 390-415. Ponce, A. 2018. "Is Welfare a Magnet for Migration? Examining Universal Welfare Institutions and Migration Flows." Social Forces 98 (1): 245-278.

Portes, A. 1997. "Immigration Theory for a New Century: Some Problems and Opportunities." International Migration Review 31 (4): 799-825.

Rotman, A., Y. Shavit, and M. Shalev. 2016. "Nominal and Positional Perspectives on Educational Stratification in Israel." Research in Social Stratification and Mobility 43: 17-24.

Schneider, S. L. 2013 "The International Standard Classification of Education 2011." Comparative Social Research 30: 365-379.

Schröder, H., and H. B. G. Ganzeboom. 2013 "Measuring and Modelling Level of Education in European Societies." European Sociological Review 30 (1): 119-136.

Smith, T. L. 1978. "Religion and ethnicity in America." American Historical Review 83 (5): 1155-85.

Solon, G. 2002. "Cross-country differences in intergenerational earnings mobility.” Journal of Economic Pespectives 16 (3): 59-66.

Telles, E. E., and V. Ortiz. 2008. Generations of Exclusion: Mexican Americans, Assimilation, and Race. New York: Russell Sage Foundation.

Thomas, W. I., and F. W. Znaniecki. 1918. The Polish Peasant in Europe and America: Monograph of an Immigrant Group. Boston: Richard G. Badger. 
van de Werfhorst, H. G., and A. Heath. 2019 "Selectivity of Migration and the Educational Disadvantages of Second-generation Immigrants in Ten Host Societies." European Journal of Population 35 (2): 347-378.

Van Tubergen, F., and H. Van De Werfhorst. 2007. "Postimmigration Investments in Education: a Study of Immigrants in the Netherlands." Demography 44 (4): 883-98.

Van Tubergen, F., I. Maas, and H. Flap. 2004 "The economic Incorporation of Immigrants in 18 Western Societies: Origin, Destination, and Community Effects." American Sociological Review 69 (5): 704-727.

Zuccotti, C. V., H. B. G. Ganzeboom, and A. Guveli. 2017. "Has Migration Been Beneficial for Migrants and Their Children?" International Migration Review 51 (1): 97-126. 


\section{Figures and Tables}

Figure 1: Share of population with tertiary education in Turkey,

Germany, France, and Netherlands between 1981 and 2017

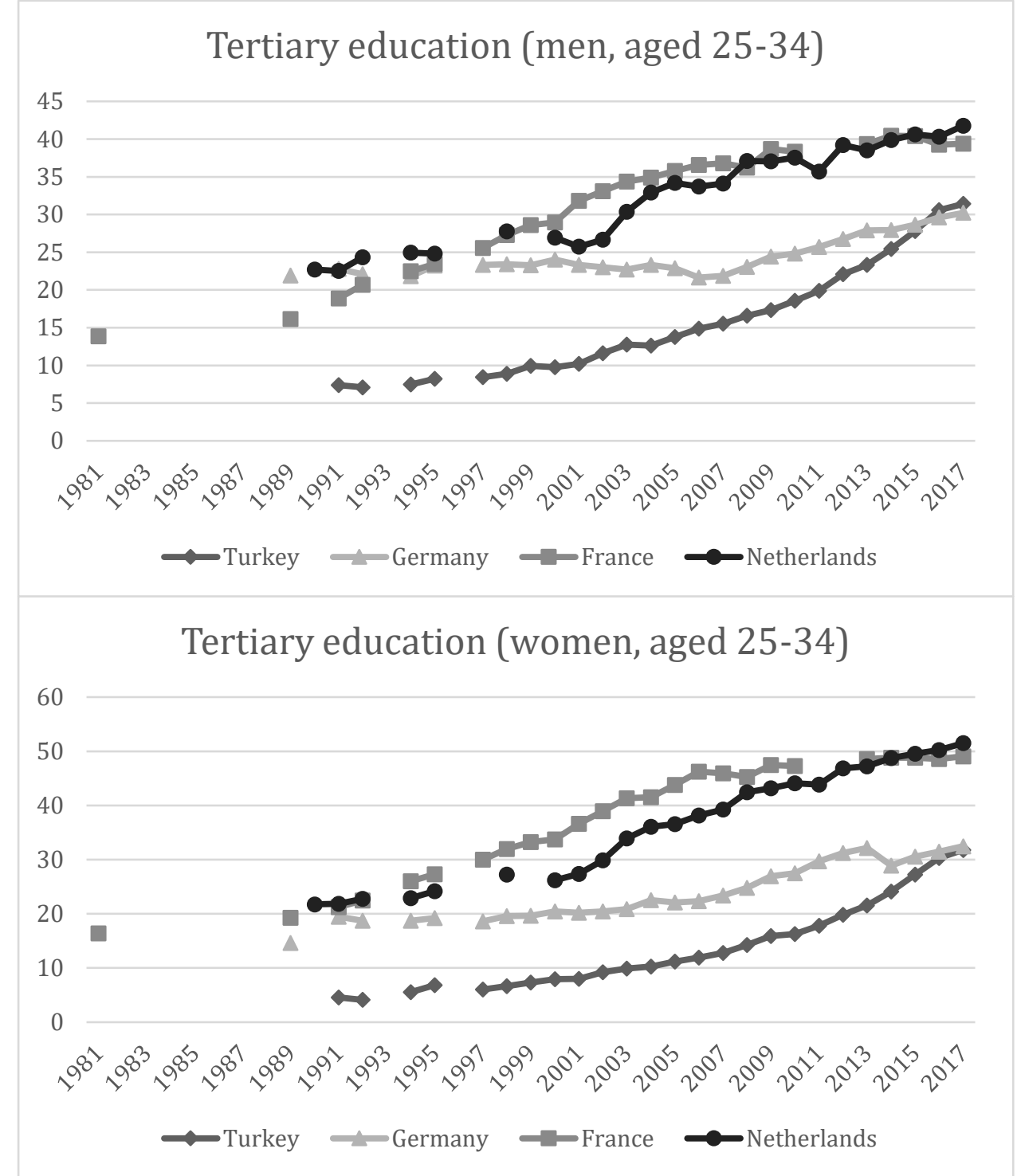

Source: OECD, 2019 - Population with tertiary education is defined as those having completed the highest level of education, by age group. 
Figure 2: Share of highest obtained education by family generations and migration status

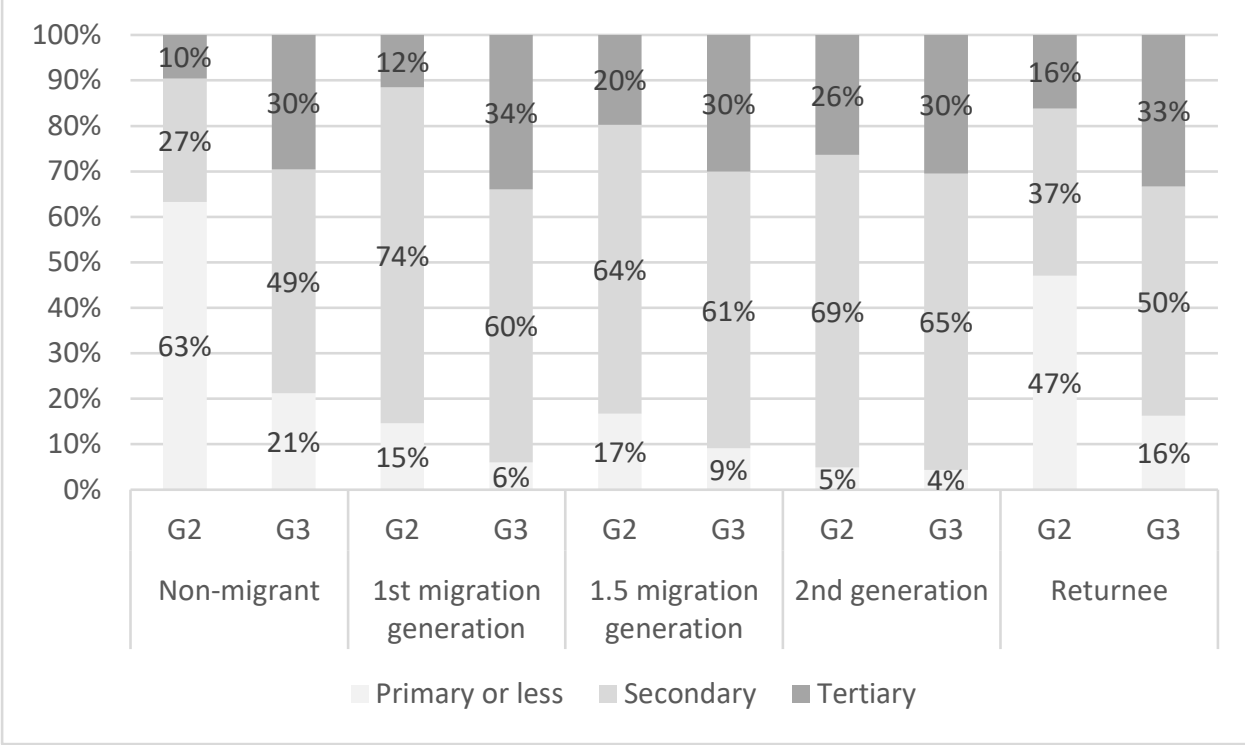


Figure 3: Share of highest obtained education by migration status and gender

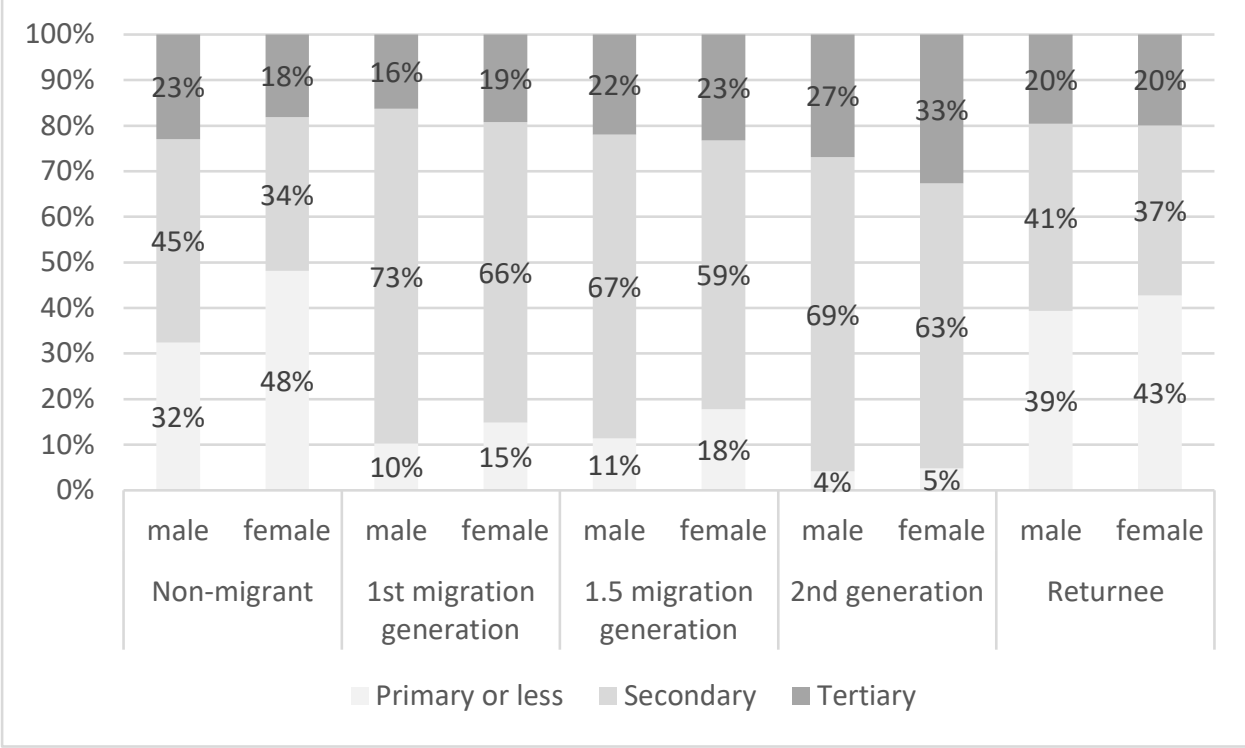


Table 1: G1 and G0 occupation and education by G1 migration status

\begin{tabular}{lccc}
\hline & Gen 0 & & Gen 1 \\
\hline & Occupation & Education & First occupation \\
\hline Gen 1 Non-migrant & 25.12 & 3.46 & 26.55 \\
Gen 1 Migrant & 24.29 & 3.61 & 25.1 \\
\hline t-value & 1.93 & -2.19 & 2.78 \\
\hline \# of cases & 1403 & 1522 & 14.99 \\
\hline
\end{tabular}


Table 2: Pooled Models - OLS Regression for Educational Outcomes

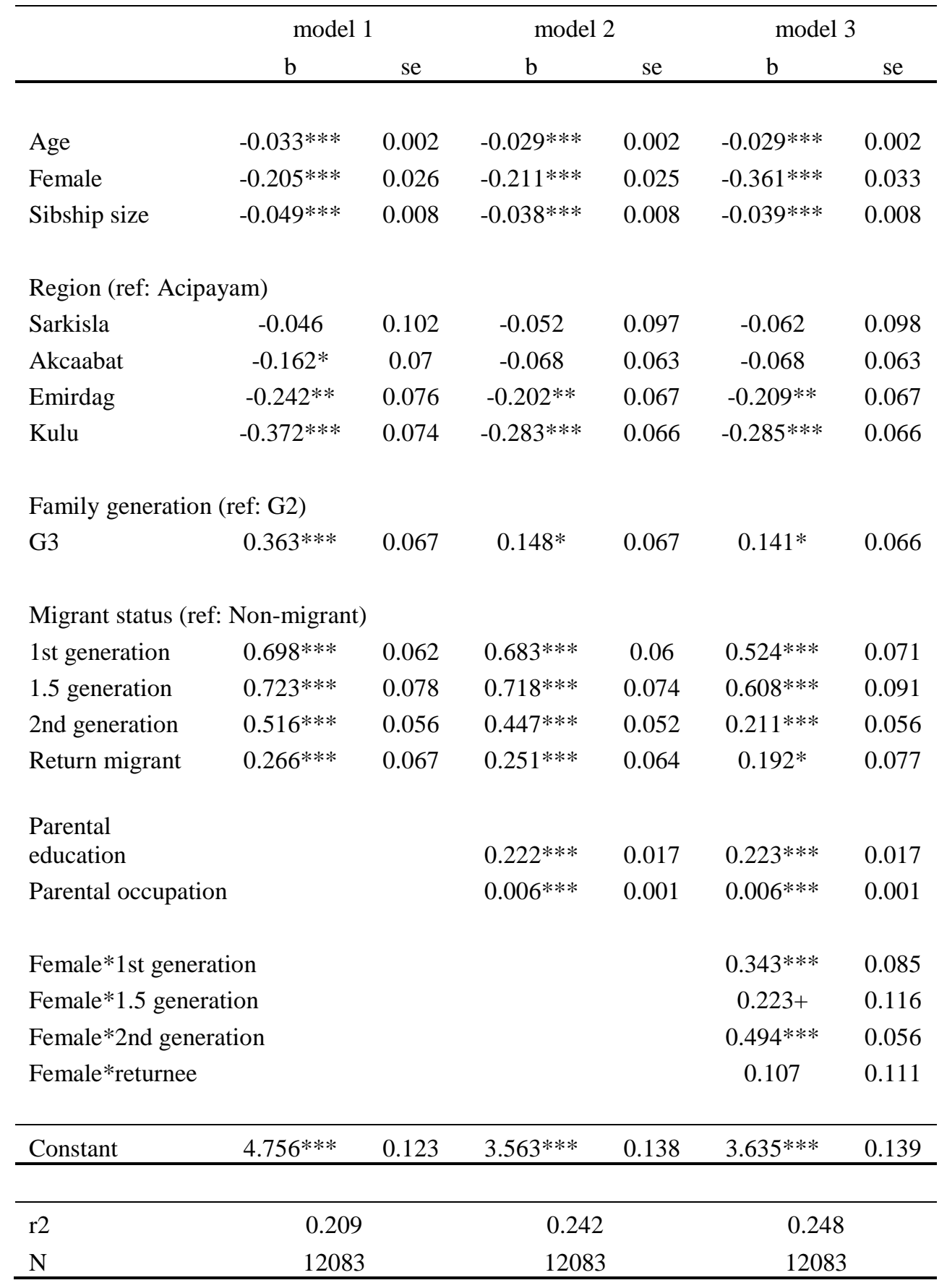

$* \mathrm{p}<.05, * * \mathrm{p}<.01, * * * \mathrm{p}<.001$

Source: 2000 Families, Proxy dataset, 2016 
Table 3: Grandparent Models - OLS Regression for educational outcomes

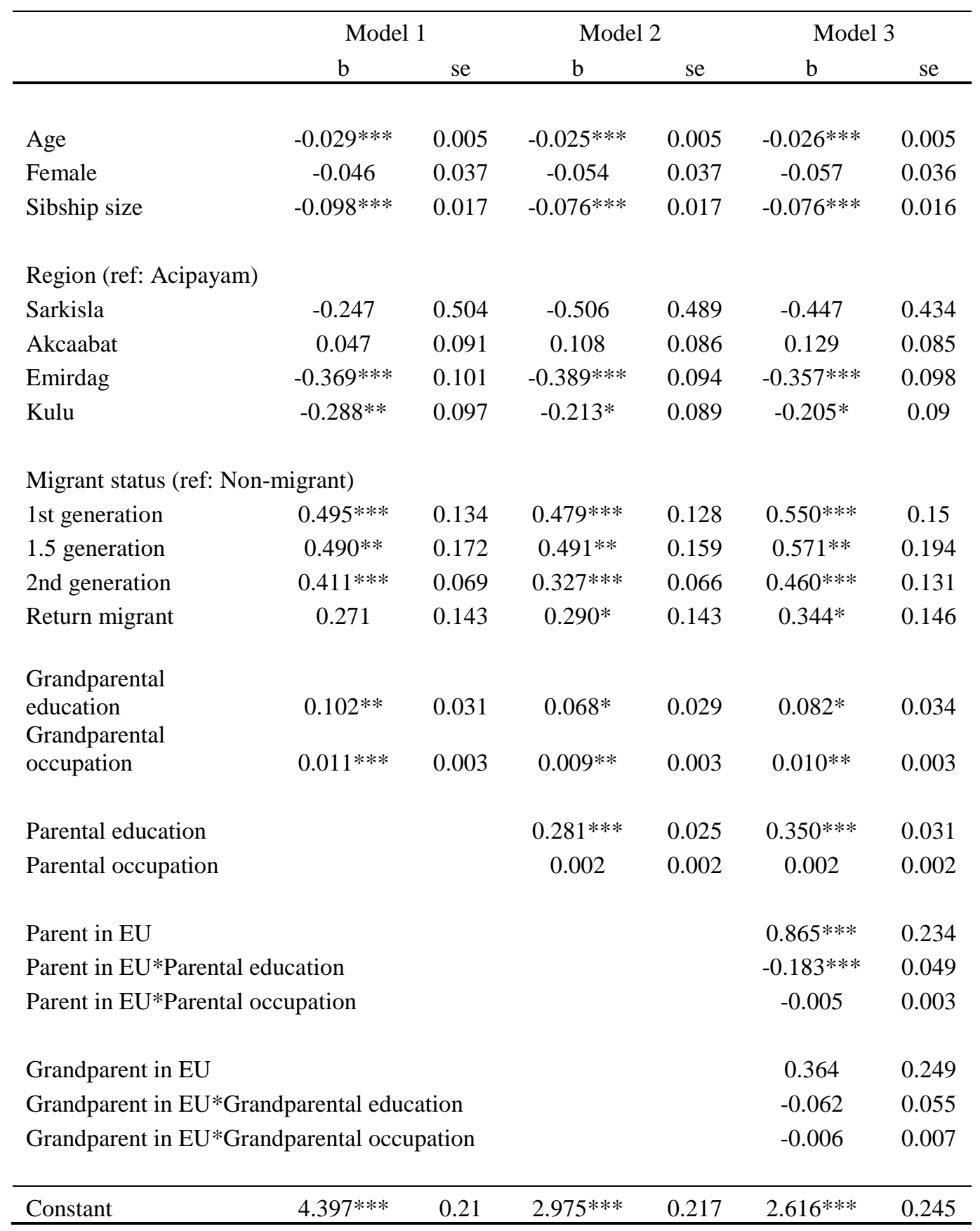

$* \mathrm{p}<.05, * * \mathrm{p}<.01, * * * \mathrm{p}<.001$

Source: 2000 Families, Proxy dataset, 2016 
Appendix A: Descriptive statistics of the variables in the analysis

\begin{tabular}{|c|c|c|c|c|c|}
\hline \multicolumn{3}{|c|}{ Gen $2 \& 3$ models } & \multicolumn{3}{|c|}{ Gen 3 models } \\
\hline & & $\%$ & & & $\%$ \\
\hline \multirow[t]{6}{*}{ Highest level of education } & Primary drop-out & 1.06 & Highest level of education & Primary drop-out & 0.25 \\
\hline & Primary & 28.15 & & Primary & 14.99 \\
\hline & Lower Secondary & 15.84 & & Lower Secondary & 15.34 \\
\hline & Higher Secondary & 32.51 & & Higher Secondary & 39.57 \\
\hline & Low Tertiary & 5.78 & & Low Tertiary & 7.15 \\
\hline & High Tertiary & 16.67 & & High Tertiary & 22.71 \\
\hline \multirow[t]{2}{*}{ Sex } & Male & 51.44 & Sex & Male & 52.19 \\
\hline & Female & 48.56 & & Female & 47.81 \\
\hline \multirow[t]{5}{*}{ Region } & Sarkisla & 4.84 & Region & Sarkisla & 0.74 \\
\hline & Acipayam & 20.72 & & Acipayam & 20.82 \\
\hline & Akcaabat & 28.71 & & Akcaabat & 32.25 \\
\hline & Emirdag & 20.24 & & Emirdag & 17.5 \\
\hline & Kulu & 25.5 & & Kulu & 28.69 \\
\hline \multirow[t]{5}{*}{ Migrant status } & Non-migrant & 61.38 & Migrant status & Non-migrant & 62.2 \\
\hline & 1st gen & 6.65 & & 1st gen & 3.07 \\
\hline & 1.5 gen & 4.25 & & 1.5 gen & 1.84 \\
\hline & 2nd gen & 22.76 & & 2nd gen & 31.12 \\
\hline & returnee & 4.95 & & returnee & 1.77 \\
\hline \multirow[t]{6}{*}{ Parental education } & Primary drop-out & 2.9 & Parental education & Primary drop-out & 3.37 \\
\hline & Primary & 53.98 & & Primary & 61.8 \\
\hline & Lower Secondary & 16.47 & & Lower Secondary & 16.03 \\
\hline & Higher Secondary & 18.32 & & Higher Secondary & 13.96 \\
\hline & Low Tertiary & 2.43 & & Low Tertiary & 1.48 \\
\hline & High Tertiary & 5.89 & & High Tertiary & 3.35 \\
\hline
\end{tabular}




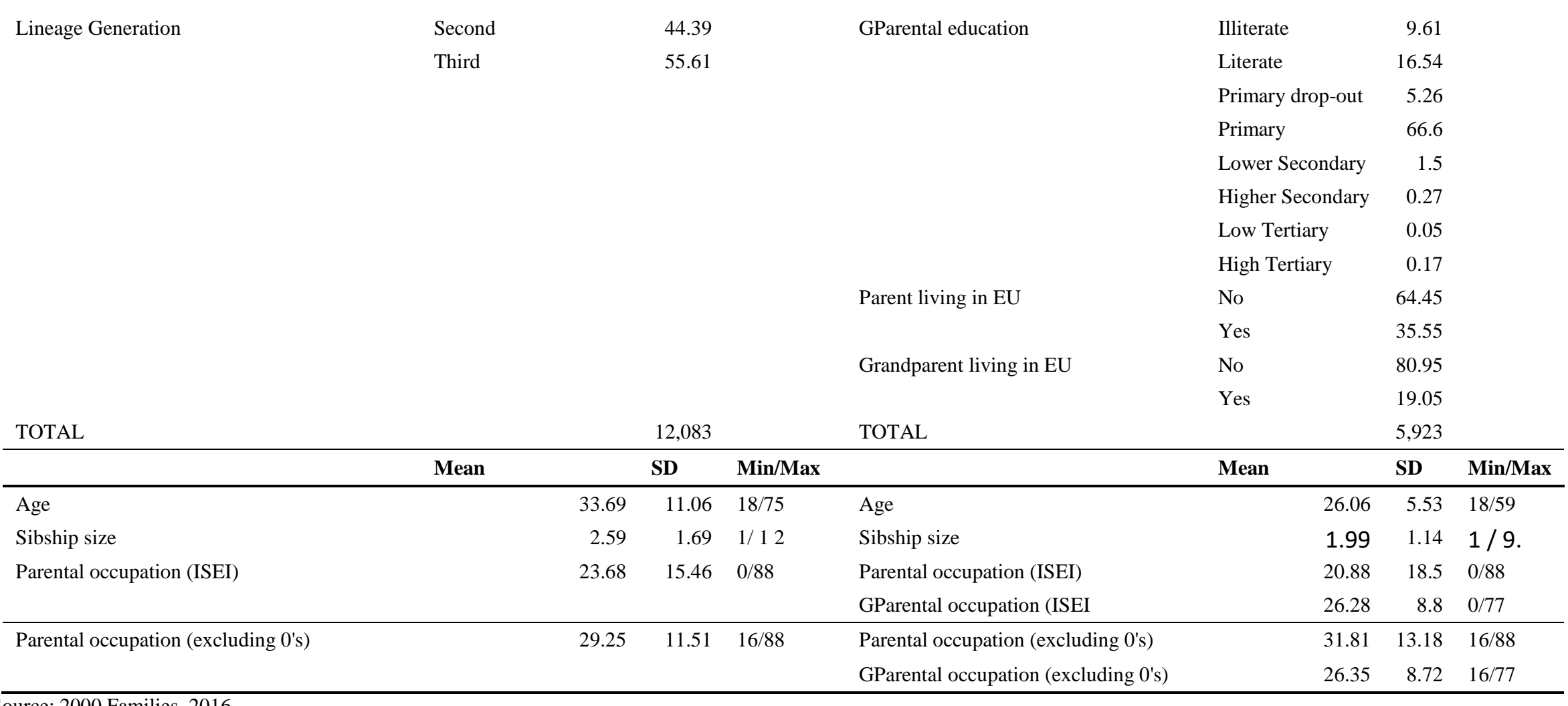

